\title{
MR Microscopy of Human Amyloid- $\beta$ Deposits: Characterization of Parenchymal Amyloid, Diffuse Plaques, and Vascular Amyloid
}

Rob J.A. Nabuurs ${ }^{\mathrm{a}, *}$, Remco Nattéb, Fenna M. de Ronde ${ }^{\mathrm{a}}$, Ingrid Hegeman-Kleinn ${ }^{\mathrm{a}, \mathrm{b}, \mathrm{c}}$, Jouke Dijkstra ${ }^{\mathrm{d}}$, Sjoerd G. van Duinen ${ }^{\mathrm{b}}$, Andrew G. Webb ${ }^{\mathrm{a}}$, Annemieke J. Rozemuller ${ }^{\mathrm{e}}$, Mark A. van Buchem ${ }^{\mathrm{a}}$ and Louise van der Weerd ${ }^{\mathrm{a}, \mathrm{f}, \mathrm{g}}$

${ }^{a}$ Department of Radiology, Leiden University Medical Center, Leiden, The Netherlands

${ }^{\mathrm{b}}$ Department of Pathology, Leiden University Medical Center, Leiden, The Netherlands

${ }^{\mathrm{c}}$ Department of Neurology, Leiden University Medical Center, Leiden, The Netherlands

${ }^{\mathrm{d}}$ Division of Image Processing (LKEB), Department of Radiology, Leiden University Medical Center, Leiden, The Netherlands

${ }^{\mathrm{e}}$ Department of Pathology, VU University Medical Center, Amsterdam, The Netherlands

${ }^{\mathrm{f}}$ Department of Anatomy and Embryology, Leiden University Medical Center, Leiden, The Netherlands

${ }^{\mathrm{g}}$ Department of Human Genetics, Leiden University Medical Center, Leiden, The Netherlands

Handling Associate Editor: Wolff Kirsch

Accepted 24 December 2012

\begin{abstract}
Cerebral deposits of amyloid- $\beta$ peptides (A $\beta$ ) form the neuropathological hallmarks of Alzheimer's disease (AD) and cerebral amyloid angiopathy (CAA). In the brain, $\mathrm{A} \beta$ can aggregate as insoluble fibrils present in amyloid plaques and vascular amyloid, or as diffuse plaques consisting of mainly non-fibrillar A $\beta$. Previously, magnetic resonance imaging (MRI) has been shown to be capable of detecting individual amyloid plaques, not only via the associated iron, but also A $\beta$ itself has been suggested to be responsible for a decrease in the image intensity. In this current study we aim to investigate the MRI properties of the different cerebral $A \beta$ deposits including diffuse plaques and vascular amyloid. Postmortem $60-\mu \mathrm{m}$-thick brain sections of $\mathrm{AD}, \mathrm{CAA}$, and Down's syndrome patients, known to contain $\mathrm{A} \beta$, were studied. High resolution $\mathrm{T}_{2}{ }^{*}$ - and $\mathrm{T}_{2}$-weighted MRI scans and quantitative relaxation maps were acquired using a microcoil on a Bruker 9.4T MRI system. Specific MRI characteristics of each type of $A \beta$ deposit were examined by co-registration of the MRI with Congo Red and $A \beta$-immunostainings of the same sections. Our results show that only fibrillar $A \beta$, present in both vascular and parenchymal amyloid, induced a significant change in $\mathrm{T}_{2}{ }^{*}$ and $\mathrm{T}_{2}$ values. However, signal changes were not as consistent for all of the vessels affected by CAA, irrespective of possible dyshoric changes. In contrast, the non-fibrillar diffuse plaques did not create any detectable MRI signal changes. These findings are relevant for the interpretation and further development of (quantitative) MRI methods for the detection and follow-up of $\mathrm{AD}$ and $\mathrm{CAA}$.
\end{abstract}

Keywords: Alzheimer's disease, amyloid- $\beta$, amyloid plaque, cerebral amyloid angiopathy, magnetic resonance imaging

\footnotetext{
*Correspondence to: Rob J.A. Nabuurs, M.Sc., Department of Radiology C2S, Leiden University Medical Center, Albinusdreef 2, 2333 ZA Leiden, The Netherlands. Tel.: +31 71 5264376; Fax: +31 71 5248256; E-mail: R.J.A.Nabuurs@LUMC.nl.
}

\section{INTRODUCTION}

Diagnosis of Alzheimer's disease (AD) in vivo remains a problematic issue. Despite recent efforts to sharpen clinical criteria, a definitive diagnosis 
still requires histopathological evidence showing the cerebral presence of amyloid- $\beta$ peptides $(A \beta)$ aggregated into amyloid plaques and neurofibrillary tangles (NFTs) [1, 2]. Although the precise role of amyloid in $\mathrm{AD}$ pathology is still not completely understood, accumulation of amyloid plaques is thought to precede the onset of the first clinical symptoms by up to two decades [3,4]. Clinical imaging techniques capable of visualizing and quantifying these early changes might enable early diagnosis.

Thus far the clinical role of magnetic resonance imaging (MRI) has been confined to depicting brain atrophy from mid-stage $\mathrm{AD}$ onwards [3]. However, clinically, MRI has not been able to detect earlier pathophysiological alterations, despite preclinical evidence that showed detection of individual amyloid plaques by MRI was feasible in postmortem human brain tissue [5-8] as well as ex vivo and in vivo in several AD mouse models [6,9-16]. The high magnetic field strength, high resolution, and long acquisition time used in these studies prohibit a direct translation of appropriate imaging protocols to the clinic. Though detection of individual plaques is not realistic in a clinical setting, quantitative $\mathrm{T}_{2}$ and $\mathrm{T}_{2}{ }^{*}$ measurements could be used to detect relaxation changes associated with amyloid plaque accumulation, or associated iron deposits, even at an image resolution that is far lower than the dimensions of amyloid deposits [9, 17]. Promising as it may be, this requires a full understanding of the MRI characteristics of all forms of $A \beta$ deposits that may be present in AD.

The most renowned type of $A \beta$ deposit in the cerebral cortex is the fibrillar plaque, which is one of the neuropathological criteria used postmortem to confirm the diagnosis of $\mathrm{AD}$. However, several other types of $A \beta$ deposits can occur in the brain. Neuropathologically, the terminology used to describe the different $A \beta$ deposits is diverse. In line with Duyckaerts et al. [18] human parenchymal $A \beta$ deposits can be divided into two main subtypes based on their $A \beta$ content: diffuse plaques and focal plaques [18]. Although the nomenclature of the different types of focal plaques is rather heterogeneous (primitive, classic, neuritic, senile, and burn-out plaques), they generally contain $A \beta$ peptides aggregated into a typical fibrillar $\beta$-sheet pleated conformation known as amyloid. For the remainder of this paper, this type of fibrillar $A \beta$ deposits are referred to as amyloid plaques. The presence of amyloid is presumed to lead to neuronal dysfunction and even the complete loss of neurons, and correlations between amyloid plaques and clinical symptoms have been reported [18].
In contrast, the so-called diffuse plaques are not specific for $\mathrm{AD}$ and although abundant in $\mathrm{AD}$ and healthy controls, they correlate poorly or not at all with dementia [19-23]. They are histopathologically defined as large, ill-defined patches of parenchymal deposits of $\mathrm{A} \beta$ peptides but with hardly to no fibrillar amyloid or dystrophic neurites present [18].

The formation of amyloid may also stretch along the vascular wall of leptomeningeal and parenchymal arteries and arterioles, and to a lesser extent the brain capillaries. This vascular amyloid is commonly referred to as cerebral amyloid angiopathy (CAA) [18, 24]. Although CAA is often found to co-exist with $\mathrm{AD}$, it can also appear as an entity on its own leading to microbleeds and severe cerebral hemorrhages [25].

Thus far, MRI studies have only examined the $\mathrm{A} \beta$-related MR contrast changes with respect to parenchymal amyloid plaques [6, 9-16]. Observed contrast changes were primarily attributed to the accumulation of iron within the plaques $[9,10,12,15]$. However, similar MRI contrast was also observed in amyloid plaques without iron, and therefore it has been hypothesized that $A \beta$ by itself contributes to the relaxation changes, presumably due to its hydrophobic nature $[6,16]$.

The aim of this study, therefore, was to study the MRI characteristics of these different types of human cerebral A $\beta$ deposits. In addition to the known induced MRI contrast changes due to the presence of amyloid plaques, we investigated the MRI characteristics of diffuse plaques and CAA in postmortem human brain material. Ultimately, a better understanding of the MRI correlates of $A \beta$ deposits may help to interpret the observed relaxation changes in quantitative MRI of AD patients.

\section{MATERIALS AND METHODS}

\section{Brain samples}

Brain tissue was obtained from the tissue bank of our institution and from the Netherlands Brain Bank (NBB). Several hours postmortem, the brains were resected, serially cut in $1 \mathrm{~cm}$ coronal sections, and stored in $4 \%$ paraformaldehyde. Routine autopsy of the brains included histological examination for CAAand AD-related pathology respectively according to Attems et al. [26] and Braak et al. [27]. Based on autopsy-confirmed diagnosis, we selected tissue from subjects suffering from diseases that are known to be associated with cerebral $A \beta$. We selected patients with $\mathrm{AD}(n=5)$, Down's syndrome (DS) $(n=1)$, CAA 
$(n=6)$, and clinically non-demented controls $(n=3)$ (Table 1). Patient anonymity was strictly maintained. All tissue samples were handled in a coded fashion, according to Dutch national ethical guidelines (Code for Proper Secondary Use of Human Tissue, Dutch Federation of Medical Scientific Societies). Previously described formalin-induced tissue artifacts that might affect MRI signal were avoided accordingly by careful visual and microscopic inspection and including material fixed for maximal 32 months [28, 29] (Table 1).

\section{Sample preparation}

MR samples were prepared according to methods that have been described previously [7]. In short, from each subject a cortical tissue block of approximately $12 \times 12 \times 10 \mathrm{~mm}^{3}$ was resected based on known predilection sides for the different types of $A \beta$. To study parenchymal deposits, samples were obtained from a coronal section that contained a section of the hippocampus to enable imaging of the neocortex in the medial temporal lobe adjacent to the entorhinal cortex. To investigate the vascular $A \beta$ deposits, tissue blocks were obtained from occipital lobe cranial within the sulcus, since the occipital lobe is the site of predilection of CAA. Remnants of the dura were removed from the pial surface, and 60 - $\mu \mathrm{m}$-thick tissue sections were cut with a vibratome (VT1000 S, Leica, Germany). Prior to imaging, any residual formalin was washed out by immersion in phosphate buffered saline
(PBS) for at least one day to partially restore transverse relaxation times [30]. Sections were mounted on a standard microscope slide covered with a drop of PBS to prevent dehydration [7]. Extreme care was taken to avoid the inclusion of any air bubbles by slowly lowering the coverslip, after which the section was sealed with nail polish.

\section{MRI acquisition and post-processing}

All MRI experiments were performed on a vertical bore 9.4 T Bruker Avance 400 WB spectrometer, equipped with a $1 \mathrm{Tm}^{-1}$ actively shielded gradient insert. As previously described, a self-resonant microcoil was placed directly on top of the sample to obtain MR images of the $60-\mu m$-thick tissue sections [7]. Multi-gradient-echo (MGE) images were acquired to assess $\mathrm{T}_{2}{ }^{*}$ with a repetition time $(\mathrm{TR})=750 \mathrm{~ms}$, echo time $(\mathrm{TE})=4-70 \mathrm{~ms}(12$ echoes with $6 \mathrm{~ms}$ spacing), flip angle $(\mathrm{FA})=30^{\circ}$, field of view $(\mathrm{FOV})=16 \times 16 \mathrm{~mm}^{2}$, data matrix $[400 \times 400]$ resulting in a resolution of $(40 \mu \mathrm{m})^{2}$ with a total data acquisition time of $6 \mathrm{~h}$ and $40 \mathrm{~min}$. $\mathrm{T}_{2}$ effects were investigated by using a multiple spin echo sequence acquired in $4 \mathrm{~h}$ and $26 \mathrm{~min}$ with $\mathrm{TR}=2000 \mathrm{~ms}$, $\mathrm{TE}=10-100 \mathrm{~ms}$ (10 echoes with $10 \mathrm{~ms}$ spacing), FOV $=16 \times 16 \mathrm{~mm}^{2}$, data matrix [200 $\left.\times 200\right]$ giving a resolution of $(80 \mu \mathrm{m})^{2}$. Post-processing was performed using a voxel-wise linear regression MatLab routine (MathWorks, Natick, MA, USA) to calculate

Table 1

Characteristics of all subjects used for this study are shown based upon clinical information and standard neuropathologic examination according to Braak criteria for thin sections [27]. Per subject the type of A $\beta$ deposits that were used for MRI analysis are stated as scored. A negative score does not necessarily imply they were not present but only that they were not included for that particular subject.

\begin{tabular}{|c|c|c|c|c|c|c|c|c|c|c|c|}
\hline \multicolumn{4}{|c|}{ Subject characteristics } & \multicolumn{8}{|c|}{ Sample scoring } \\
\hline No. & $\begin{array}{c}\text { Age/ } \\
\text { Gender }\end{array}$ & Diagnosis & Braak & $\begin{array}{l}\text { Cause of } \\
\text { death }\end{array}$ & $\begin{array}{c}\text { Fixation } \\
\text { period (months) }\end{array}$ & $\begin{array}{c}\text { Normal } \\
\text { GM }\end{array}$ & $\begin{array}{l}\text { Diffuse } \\
\text { plaques }\end{array}$ & $\begin{array}{l}\text { Amyloid } \\
\text { plaques }\end{array}$ & CAA & dysCAA & capCAA \\
\hline 1 & $23 / \mathrm{F}$ & Control & 0 & Myocarditis & 26 & scored & - & - & - & - & - \\
\hline 2 & $83 / \mathrm{F}$ & Control & 2 & Arrhythmia & 26 & scored & - & - & - & - & - \\
\hline 3 & $89 / \mathrm{F}$ & Control & 3 & Myocardial infarct/Pneumonia & 20 & - & scored & scored & - & - & - \\
\hline 4 & $60 / \mathrm{F}$ & $\mathrm{AD}$ & 5 & Cachexia/dehydration & 25 & - & scored & scored & - & - & - \\
\hline 5 & $77 / \mathrm{M}$ & $\mathrm{AD}$ & 6 & Cachexia/dehydration & 26 & - & scored & scored & - & - & - \\
\hline 6 & $85 / \mathrm{F}$ & $\mathrm{AD}$ & 4 & Aspiration pneumonia & 26 & - & scored & scored & - & - & - \\
\hline 7 & $87 / \mathrm{M}$ & $\mathrm{AD}$ & 5 & Cachexia/dehydration & 25 & - & scored & scored & - & - & - \\
\hline 8 & $88 / \mathrm{F}$ & $\mathrm{AD}$ & 4 & Unknown & 17 & - & scored & scored & - & - & - \\
\hline 9 & $31 / \mathrm{M}$ & DS & 0 & Myocardial infarct & 23 & scored & scored & - & - & - & - \\
\hline 10 & $72 / \mathrm{M}$ & sCAA & 3 & Intracerebral hemorrhage & 32 & - & - & - & scored & - & - \\
\hline 11 & $57 / \mathrm{M}$ & $\mathrm{AD} / \mathrm{sCAA}$ & 6 & Intracerebral hemorrhage & 30 & - & - & - & scored & scored & - \\
\hline 12 & $84 / \mathrm{M}$ & sCAA & 1 & Pneumonia & 22 & - & - & - & scored & - & scored \\
\hline 13 & $61 / \mathrm{F}$ & sCAA & 0 & Intracerebral hemorrhage & 4 & - & - & - & scored & - & - \\
\hline 14 & $80 / \mathrm{M}$ & sCAA & 2 & Pneumonia & 32 & - & - & - & scored & scored & - \\
\hline 15 & $81 / \mathrm{M}$ & sCAA & 3 & Hemorrhagic infarcts & 5 & - & - & - & scored & scored & - \\
\hline
\end{tabular}

AD, Alzheimer's disease; CAA, cerebral amyloid angiopathy; DS, Down's syndrome; sCAA, sporadic CAA; dysCAA, dyshoric CAA; capCAA, capillary CAA; GM, gray matter. 
quantitative $\mathrm{T}_{2}{ }^{*}$ and $\mathrm{T}_{2}$ maps. $\mathrm{T}_{2}$ - and $\mathrm{T}_{2}{ }^{*}$-weighted images were created as the sum of the third to the tenth echo image.

Despite extreme care in sample preparation, MRI hypointensities related to small inhomogeneities caused either by external dust particles, or tiny air bubbles were unavoidable. These artifacts were present throughout all samples, and were excluded from the analysis based on visual microscopic inspection of the sample.

\section{Congo red staining for amyloid}

After MRI acquisition, Congo Red staining was performed for detection of amyloid on the same control, DS, and AD sections that were analyzed by MRI. After removing the coverslip, the free floating tissue section was rinsed in distilled water three times for 10 min each. The section was counterstained with Harris' haematoxylin and rinsed in tap water for $10 \mathrm{~min}$. After pretreatment of $20 \mathrm{~min}$ with $3 \% \mathrm{NaCl}$ and $0.01 \%$ $\mathrm{NaOH}$ in $80 \% \mathrm{EtOH}$, the free floating section was again immersed in the same solution for 20 min with $0.5 \%$ Congo Red. The section was rinsed briefly in, in turn, $96-80-70-0 \%$ EtOH in distilled water and airdried prior to mounting (Micromount). This additional rehydration step with pure distilled water reversed most non-uniform shrinkage caused by the ethanol, thereby simplifying subsequent coregistration with the MRI data. Directly thereafter the section was digitized using a bright field microscope scanner (Pannoramic MIDI, 3DHistech, Hungary). Congo Red stained amyloid was confirmed using depolarized light, under which the red stained areas gave a characteristic green birefringence.

\section{A $\beta$ immunostaining}

To detect all isoforms of $\mathrm{A} \beta$, including the diffuse plaques, a standard immunostaining procedure using a commercial monoclonal antibody (6F/3D, DakoCytomation, Denmark) was applied [31]. The sections that had previously undergone Congo Red staining had the coverslip removed by overnight immersion in xylene, and were rehydrated using $96-80-70$ $-0 \% \mathrm{EtOH}$ in distilled water. During this process, both Congo Red and haematoxylin were completely removed. Endogenous peroxidase activity was blocked by applying $0.3 \% \mathrm{H}_{2} \mathrm{O}_{2}$ in methanol for $20 \mathrm{~min}$. For antigen retrieval, the samples underwent $1 \mathrm{~h}$ immersion in $85 \%$ formic acid, rinsing with distilled water and $\mathrm{PBS}$, and $30 \mathrm{~min}$ immersion at $37^{\circ} \mathrm{C}$ in $0.1 \%$ trypsin (Type II-S, Sigma) with $0.1 \% \mathrm{CaCl}_{2}$ at $\mathrm{pH}$ 7.4. Next, the floating sections were incubated overnight with a $1: 10$ dilution of $\mathrm{A} \beta$-antibody in $1 \% \mathrm{BSA}$ in PBS at room temperature, and rinsed three times for $10 \mathrm{~min}$ each with PBS before biotinylated RAM secondary antibodies ( $1: 200$, DakoCytomation, Denmark) in $1 \%$ BSA in PBS were added for $1 \mathrm{~h}$. Next, the sections were rinsed three times with PBS and incubated for $30 \mathrm{~min}$ with freshly prepared HRP-labeled avidin-biotin complex (ABC, Vector Labs, CA, USA). Enhancement was completed by 5-10 min immersion in $100 \mathrm{ml}$ distilled water containing $0.075 \%$ 3, 3'-diaminobenzidine (DAB) (Sigma) and $15 \mu \mathrm{l}$ of $30 \% \mathrm{H}_{2} \mathrm{O}_{2}$ after which the reaction was stopped in distilled water. The section was then mounted and digitized.

\section{Coregistration and ROI analysis}

For each section, the processed images were stacked prior to co-registration with their corresponding histology using the Cyttron visualization platform (CVP, Leiden, the Netherlands) and Adobe Photoshop CS3 (Adobe). Based on evaluation by a neuropathologist (R.N.), the A $\beta$ positive areas on immunohistochemistry that were also Congo Red positive were classified as amyloid plaques. The poorly-defined larger patches of parenchymal $A \beta$ were classified as diffuse plaques based on both their morphology and the lack of Congo Red staining according to the previous nomenclature [18]. Further analysis included only those areas that clearly contained only a single subtype of $A \beta$ deposition. CAA-loaded vessels were selected based on their distinct vascular morphology present in the immunostaining. Areas completely devoid of any staining were classified as normal appearing gray matter (GM). Based on these classifications, $\mathrm{T}_{2}{ }^{*}$ - and $\mathrm{T}_{2}$-weighted images were analyzed to detect any corresponding changes in the MRI signal related to the specific $A \beta$ deposits. Quantitative $\mathrm{T}_{2}{ }^{*}$ and $\mathrm{T}_{2}$ relaxometry of the different parenchymal $A \beta$ deposits was assessed by region-of-interest (ROI) analyses based on the aforementioned areas using the Image $J$ software package (National Institutes of Health, Bethesda, MA, USA). For amyloid plaques, an ROI of a single voxel was used since this corresponds best to the size of the plaques. In contrast, for the areas containing diffuse plaques, the ROI consisted of multiple voxels corresponding to the plaque's outline on histology. To assess normal-appearing GM, several ROIs of 100 voxels were selected in anatomically-similar cortical areas. Measurements across all samples were combined to calculate averages for each type of $\mathrm{A} \beta$ deposit. Possible differences in relaxation times for each subtype 
were tested using a Student $t$-test, with $p$-values $<0.05$ considered statistically significant.

\section{RESULTS}

\section{Parenchymal A $\beta$ deposits}

All samples were taken from similar neo-cortical regions of the middle temporal lobe, and formalin fixation periods were between 3-24 months. Both diffuse and amyloid plaques were present in all samples except for two control subjects 1 and 2, and subject 9, whom only contained diffuse plaques. The distribution of both types of parenchymal $A \beta$, however, often co-localized with each other which hampered the selection for further analysis. As we aimed to select only those areas containing a single type of deposition, diffuse and amyloid plaques could not be scored an all samples. The scored amyloid types and other characteristics of each subject are presented in Table 1.

\section{$T_{2}{ }^{*}$ - and $T_{2}$-weighted MRI}

On visual inspection of the $\mathrm{T}_{2}{ }^{*}$ - and $\mathrm{T}_{2}$-weighted scans by trained observers, only the congophilic amyloid plaques were visible as hypointense foci (Fig. 1).
Congophilic amyloid plaques with smaller diameters than the MRI voxel size were less conspicuous on MRI due to the partial volume effect. In general, the signal attenuation was more pronounced on the $\mathrm{T}_{2}{ }^{*}$ weighted images; however, the resolution of the $\mathrm{T}_{2}$ weighted images was four times lower than the $\mathrm{T}_{2}{ }^{*}$-weighted images due to time restrictions. Despite the large amount of $\mathrm{A} \beta$ present in the diffuse plaques, their presence did not result in any visible change in MRI contrast as compared to the surrounding GM in either sequence. This was most strikingly seen on close examination of cortical sections of subject 9, who was diagnosed with Down's syndrome, showing abundant parenchymal $\mathrm{A} \beta$ deposits but completely lacking fibrillar amyloid (Fig. 2). MR images of normal appearing GM showed no cortical hypointensities apart from tissue preparation-induced artifacts (Fig. 3).

\section{Quantitative $T_{2}{ }^{*}$ and $T_{2}$ relaxation}

Similar to the visual assessment, only the amyloidbearing deposits were associated with a significant decrease in $\mathrm{T}_{2}{ }^{*}$ and $\mathrm{T}_{2}$ relaxation times (Fig. 4). Further quantification of these findings by ROI analysis demonstrated that cortical areas containing diffuse plaques $\left(\mathrm{T}_{2}=63.4 \pm 3.1 \mathrm{~ms}\right.$ (mean $\left.\pm \mathrm{SD}\right) ; p=0.051$;
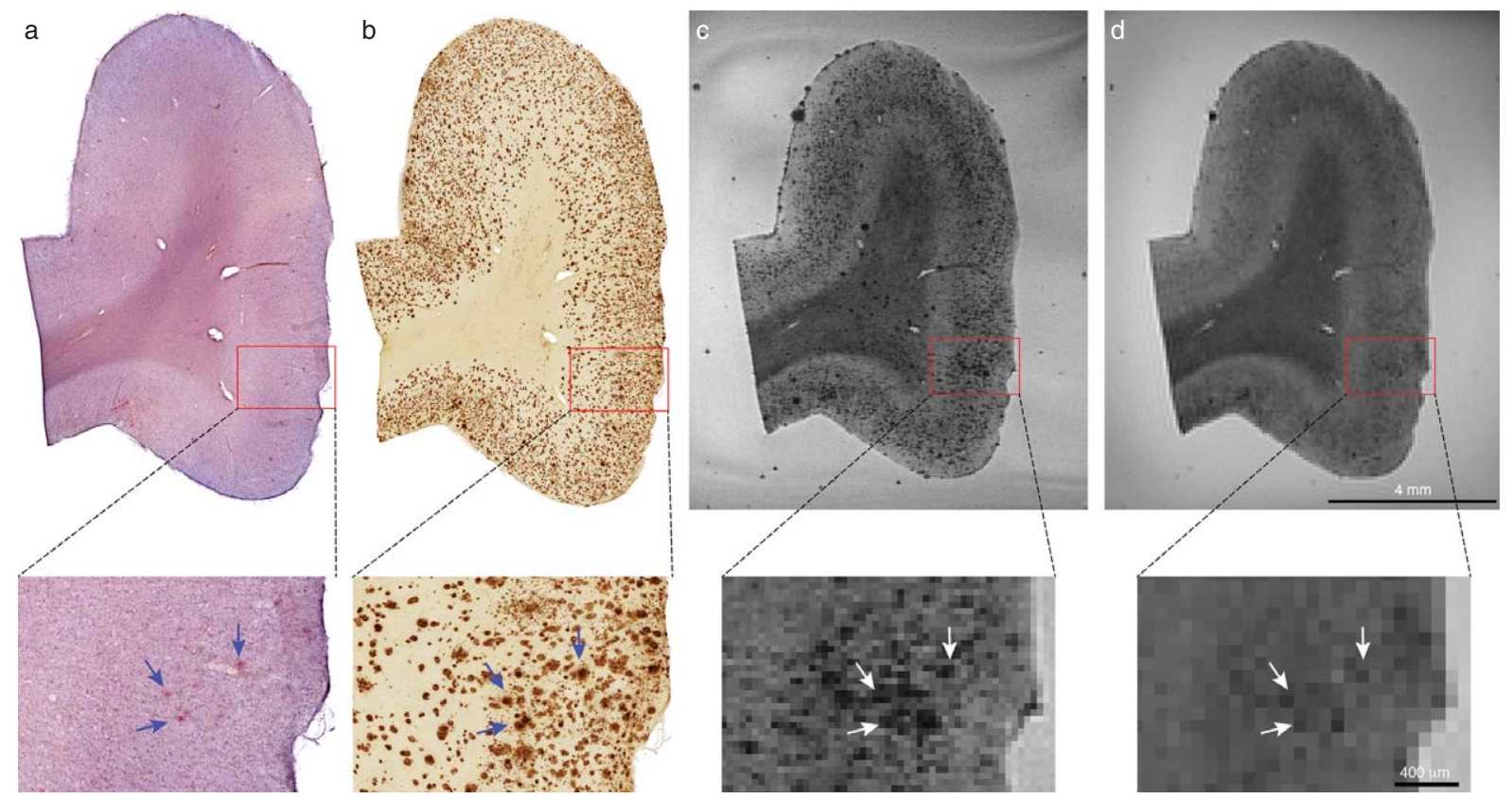

Fig. 1. Co-registration of (a) Congo Red and (b) A $\beta$ stained section with corresponding (c) $\mathrm{T}_{2}{ }^{*}$ - and (d) $\mathrm{T}_{2}$-weighted MR image from subject 4 diagnosed with Alzheimer's disease. The inhomogeneous signal in the cortex appeared to be caused by the deposition of A $\beta$ into amyloid plaques: their distribution corresponded to the hypointensities as detected on both types of MR images. As an example, the more detailed comparison showed several larger amyloid plaques to be co-localized with these hypo-intensities (arrows). Those smaller in size, or corresponding to a lesser amount of CR staining, were more difficult to discriminate. The structural layering of the GM, visible in both MR images, appeared to be independent of the $A \beta$ distribution. 

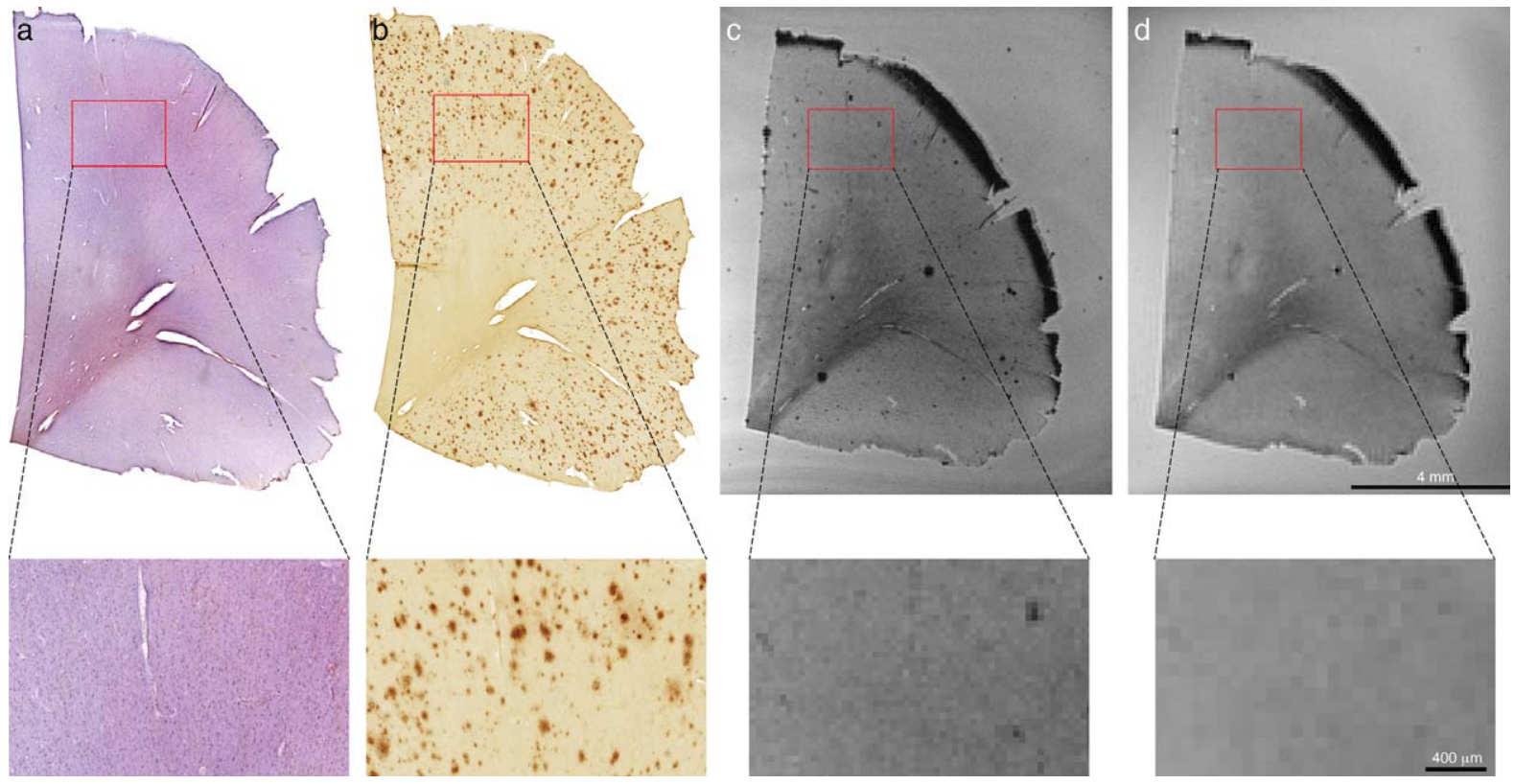

Fig. 2. Co-registration of (a) Congo Red and (b) A $\beta$ stains with the corresponding (c) $\mathrm{T}_{2}{ }^{*}$ - and (d) $\mathrm{T}_{2}$-weighted MR images of subject 9 diagnosed with Down's syndrome. Since all A $\beta$ deposits lacked Congo Red staining, they were classified as diffuse plaques, which resulted in a relatively homogenous MR image. No A $\beta$ specific changes in MR signal intensity could be discriminated.

$\left.\mathrm{T}_{2}{ }^{*}=47.3 \pm 6.2 \mathrm{~ms} ; p=0.28\right)$ were not associated with a significant difference in either $\mathrm{T}_{2}$ or $\mathrm{T}_{2}{ }^{*}$ relaxation when compared to normal appearing GM $\left(\mathrm{T}_{2}=55.1 \pm 2.5 \mathrm{~ms} ; \mathrm{T}_{2}{ }^{*}=47.5 \pm 4.7 \mathrm{~ms}\right)$ (Fig. 5). In contrast, focal amyloid-bearing deposits showed a significant reduction in $\mathrm{T}_{2}$ and particularly in $\mathrm{T}_{2}{ }^{*}$ relaxation times $\left(\mathrm{T}_{2}=49.9 \pm 10.0 \mathrm{~ms} ; \mathrm{T}_{2}{ }^{*}=17.7 \pm 6.4 \mathrm{~ms}\right)$ when compared to normal appearing GM.

\section{Vascular amyloid}

Several subtypes of CAA were present within the subjects which, based upon the $A \beta$ immunostaining, could be classified as: a) "large vessel" CAA without, or b) "large vessel" CAA with dyshoric changes (i.e., amyloid extending outside the vascular wall into the parenchyma), or c) capillary CAA (Table 1). In four subjects, more than one subtype of CAA was present, while capillary CAA, which is relatively rare, was only detected in one subject. None of the selected occipital sections showed evidence of microbleeds or aneurysms that are known to often accompany CAA.

Capillary CAA did not result in any detectable MR contrast change on either the $\mathrm{T}_{2}{ }^{*}$ - or $\mathrm{T}_{2}$-weighted images. However, the large CAA-bearing vessels themselves were observed as hypointense structures in both scans, irrespective of accompanying dyshoric changes (Fig. 6). These findings were, however, not consistent for all large CAA vessels, as we also observed CAA vessels with a similar histological appearance, but without any signal attenuation on MRI. These large variations in appearance on MRI combined with the low number of subjects restricted further quantitative ROI analyses for CAA.

\section{DISCUSSION}

Previous studies have suggested that $A \beta$, irrespective of associated iron, might induce detectable MRI contrast. Our data, however, demonstrate that the mere presence of large amounts of $A \beta$ peptides alone is not sufficient to change $T_{2}$ or $T_{2}{ }^{*}$ relaxation significantly, since diffuse plaques are not associated with intensity changes on the MR images. Only when $A \beta$ is deposited in its fibrillar amyloid conformation are $\mathrm{T}_{2}{ }^{*}$ and $\mathrm{T}_{2}$ relaxation times reduced, which can be observed as the punctuate hypointensities described in previous studies [5-16]. In addition, this study also showed that direct visualization of vascular amyloid is possible, although signal attenuation was not observed in all CAA-affected vessels. With regard to the cerebral presence of $A \beta$, this would imply that quantitative MRI would depict the cerebral fibrillar amyloid load rather than the amount of cerebral $A \beta$ peptides.

The current study used a magnetic field strength and spatial resolutions that are not clinically applicable; 

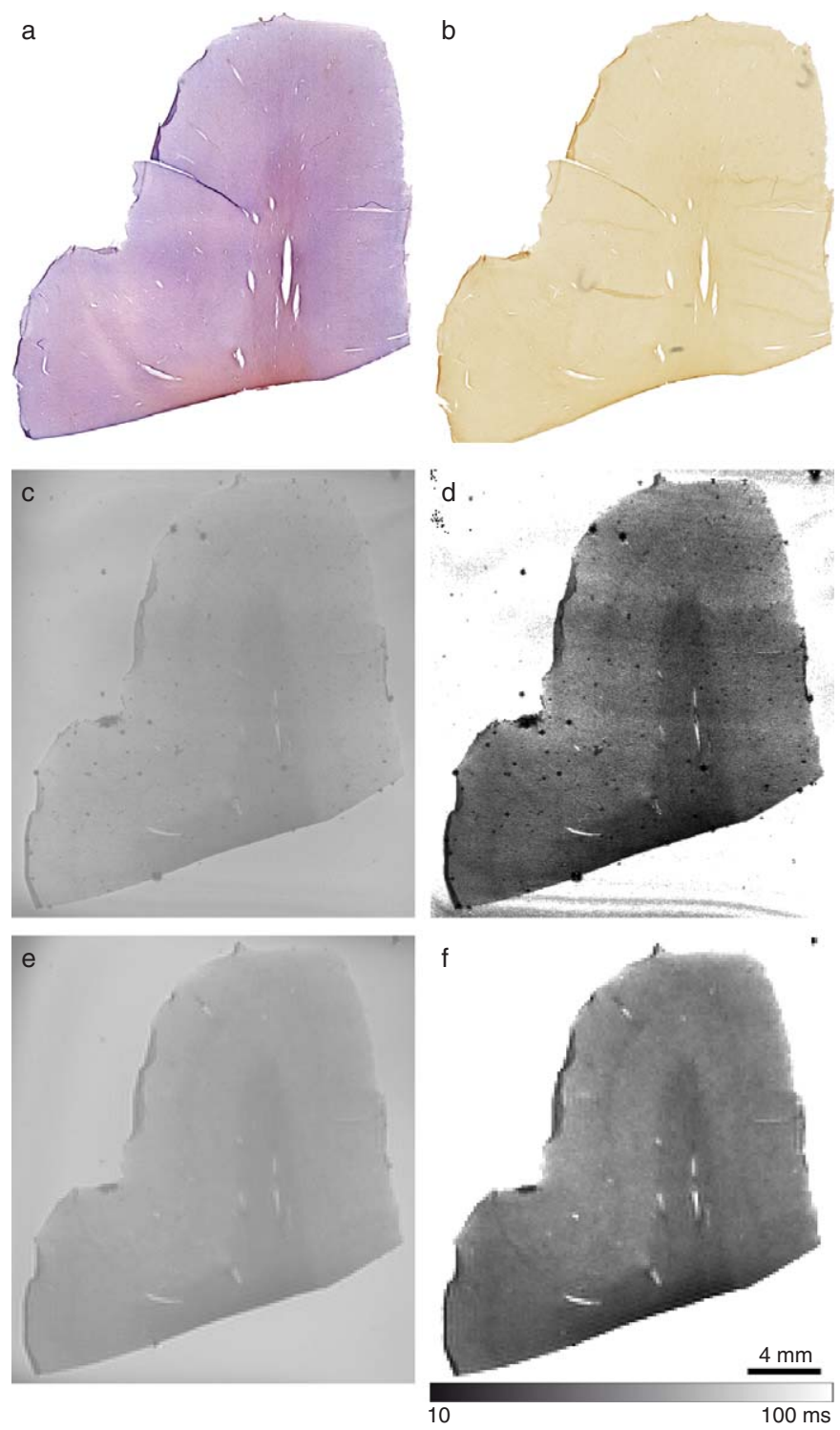

Fig. 3. Co-registration of (a) Congo Red and (b) A $\beta$ stains with the corresponding (c) $\mathrm{T}_{2 *}$ - weighted image and (d) $\mathrm{T}_{2}{ }^{*}$ map, and (e) $\mathrm{T}_{2}$-weighted image and (f) $T_{2}$ map of control subject 2 . No inhomogeneous hypointensities were found within the GM since no $A \beta$ was present. Small circular hypointensities were observed both on and next to the section due to the inclusion of small air pockets underneath the coverslip.

however, this study of the neocortical $A \beta$ deposits may provide background information that can support the development of future clinical (quantitative) MRI methods. Currently clinical scans do not allow the detection of individual plaques limited by the maximum resolution. We therefore did not aim to colocalize individual amyloid plaques, but tried to characterize which types of $A \beta$ deposits produce changes in MRI signal.

Diffuse plaques are hypothesized to be pathologic and are suggested to function as a seeding point for amyloid plaques. However, they are not specific for $\mathrm{AD}$, they do not correlate with severity of dementia, and clinical evidence regarding their role in the pathogenesis of AD has not yet been reported [19-23]. In contrast, amyloid plaques are considered to be one of the definitive hallmarks of $\mathrm{AD}$, and thus their presence forms one of the diagnostic criteria for AD. Any imaging technique aiming at the detection of amyloid should be sure to preclude the assignation of the $A \beta$ deposited as diffuse plaques, especially since they are often found to be present in large quantities (Fig. 4). 

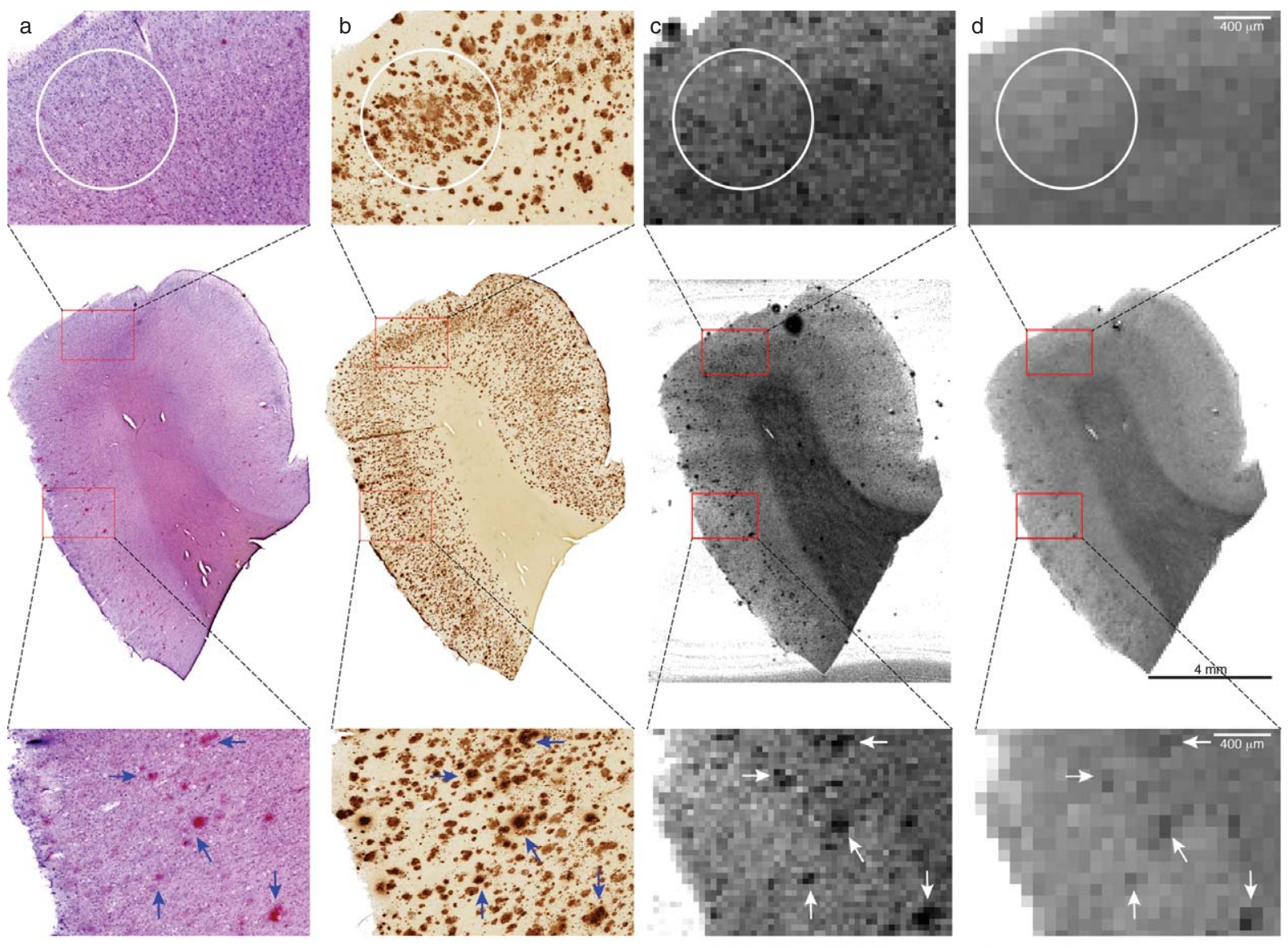

10

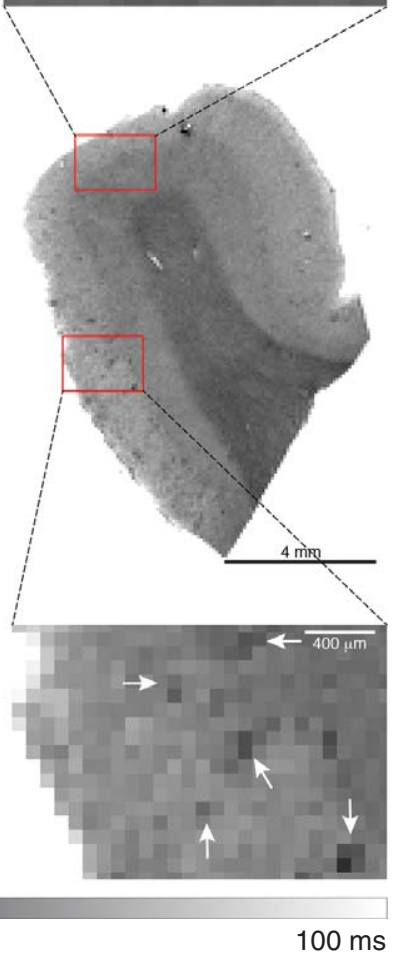

Fig. 4. Co-registration of (a) Congo Red and (b) $A \beta$ stains with corresponding quantitative (c) $T_{2}{ }^{*}$ and (d) $T_{2}$ maps of subject 5. No signal decrease was observed corresponding to the outline of areas with $A \beta$ lacking $C R$ positivity (white circle). In contrast, as an example several but not all amyloid plaques highlighted by the presence of both CR and $A \beta$ clearly resulted in hypo-intensities seen on the corresponding MR images (arrows).

The current clinical standard for in vivo amyloid plaque detection uses $\left[{ }^{11} \mathrm{C}\right]$-Pittsburgh-B compound $(\mathrm{PiB})$ as an imaging tracer for positron emission tomography (PET). Numerous studies have demonstrated its specificity and sensitivity for plaque detection, showing that $\mathrm{PiB}$ binding is highly selective for fibrillar $\mathrm{A} \beta$ deposits in $\mathrm{AD}$ [32]. However, its ability to delineate diffuse plaques and even NFTs has also been reported in a postmortem study [33]. Furthermore, in cases of patients with other types of dementias, such as Parkinson's disease with dementia, and dementia with Lewy bodies, correlation of in vivo ${ }^{11} \mathrm{C}$-PiB with postmortem neuropathology showed that the high ${ }^{11} \mathrm{C}-\mathrm{PiB}$ retention in these patients was primarily correlated to the presence of diffuse plaques [34, 35]. Thus, in the setting of these dementias, ${ }^{11} \mathrm{C}-\mathrm{PiB}$ PET has insufficient specificity for in vivo diagno- sis of comorbid $\mathrm{AD}$ due to its inability to distinguish between diffuse and neuritic amyloid plaques [34]. In these cases in particular, MRI could provide additional value to confirm the presence of amyloid plaque.

In addition to investigating parenchymal $\mathrm{A} \beta$, this study is the first to present findings regarding MRI detection of vascular amyloid, another major site of cerebral $A \beta$ deposition. Besides being present in the vast majority of $\mathrm{AD}$ cases, $\mathrm{CAA}$ is an entity in itself and a common age-related finding at autopsy [1]. CAA leads to local inflammatory responses and loss of vessel wall integrity that eventually result in lobar hemorrhages, as well as complete and partial infarcts [30]. Thus far, only these secondary CAA-related pathologies have been reported to be detectable by MRI, but not the vascular amyloid accumulations themselves $[11,26]$. Our results showed that several CAA-affected 

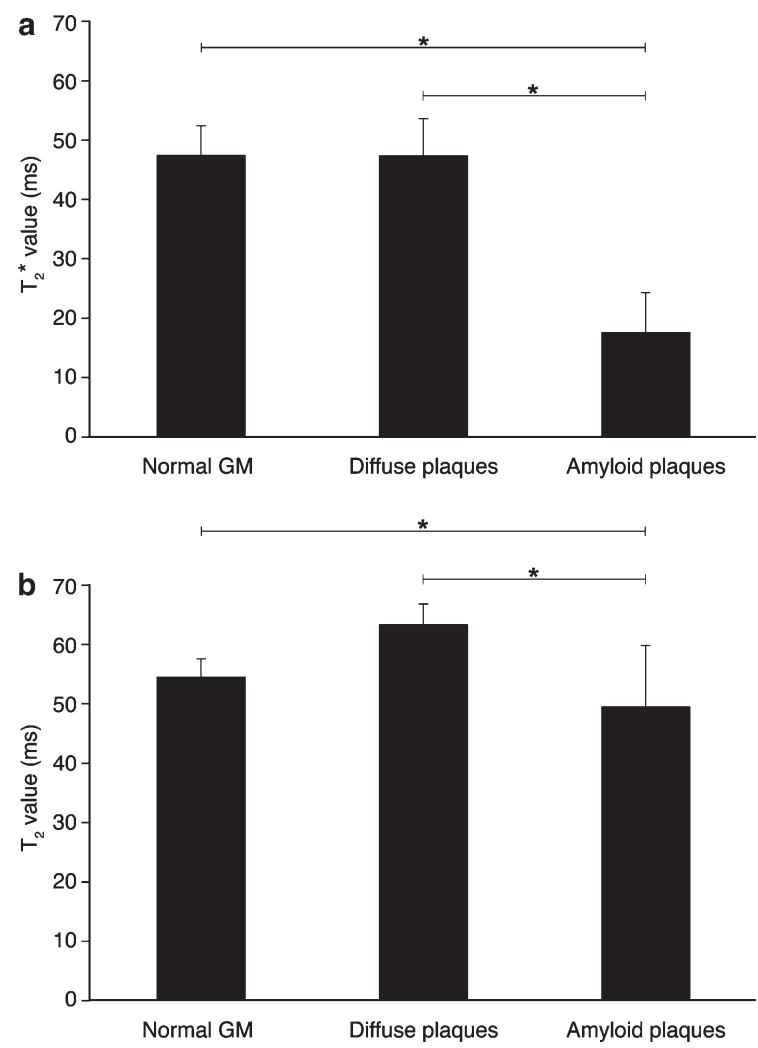

Fig. 5. Bar graphs of average (a) $\mathrm{T}_{2}{ }^{*}$ and (b) $\mathrm{T}_{2}$ values in milliseconds (ms) resulting for ROI analyses of all samples for normal appearing GM $(n=21)$, diffuse plaques $(n=26)$, and amyloid plaques $(n=40) .{ }^{*}$ Significant difference of $p<0.05$ after an unpaired two-tailed Student $t$-test. Error bars represent the standard deviation.

vessels are associated with linear hypointensities. As these closely followed the outline of the CAA, this suggests that CAA itself in principle should be detectable with MRI.

However, not all CAA-affected vessels resulted in a similar loss of MR signal. Besides having vascular amyloid as a common denominator, various differences can be found among CAA [30]. These include not only the amount of $A \beta$ deposition but also its position within the vascular wall, vasculature fragmentation and loss of structure, formation of fibrinoid necrosis, iron accumulation, and signs of hemorrhages or microaneurysms. The current study was limited as its current setup did not allow us to take these differences into account, though these might explain the variation in MRI results found within the present CAA data.

In contrast to amyloid plaques, the usual site for the development of CAA is the occipital lobe rather than the medial temporal lobe. Besides differences in clinical appearance, the spatial pattern of areas of signal loss might be used for differentiation between parenchymal and vascular amyloid, analogous to the different distribution seen on PiB-PET images in CAA and AD patients [17]. Additionally, depending on spatial resolution, the typical tubular structure of amyloid-laden vessels might be a distinctive feature of CAA.

An effort was made to assess the contribution of capillary CAA to MR signal intensity. Compared to the other types, capillary CAA is a rather rare finding but its presence correlates well with clinical symptoms such as dementia [28]. It was present in only one sample of all our subjects. In this sample, direct detection of amyloid on the $\mathrm{T}_{2 *}$-weighted MRI was hampered mainly by the small vessel size and the location of the capillary CAA within or near the stria of Gennari, a cortical layer of the occipital cortex known to result in a loss of signal using these sequences [9]. Further MRI studies including more capillary CAA samples will be essential to state with confidence whether capillary CAA leads to signal changes on MRI.

The possible effects of chemical fixation of tissue when acquiring postmortem MRI data should always be taken into consideration and form an important limitation in the direct clinical translation of these types of studies [28]. Known effects such as altered water diffusion properties, reduced relaxation parameters, and tissue changes due to prolonged fixation can be minimized by including only samples subjected to a well-defined, limited, fixation period and by thoroughly washing the sample with PBS to partially restore transverse relaxation times $[28,30]$. This cannot, however, compensate for possible effects on $\mathrm{T}_{2 *}$ caused by protein cross-linking. In addition, tissue iron concentration is known to decrease due to prolonged formalin fixation, which influences MRI parameters $[26,36]$. Whether this iron wash-out differs between the distinct types of $\mathrm{A} \beta$ deposits remains unknown. With regard to this study, most samples were fixated for a similar period of just over two years, including the controls (Table 1), which makes it unlikely that the reported differences in MRI signal were induced by differences in fixation. Future studies may include the use of fresh unfixed tissue as to circumvent these possible fixation effects [37]. The $60-\mu \mathrm{m}$-thick sections required for the direct one-to-one correlation as performed within this study, however, hampers the use of fresh non-frozen tissue due to technical difficulties with sectioning and mounting of the tissue.

Iron has been indicated to play an important role in the MR contrast of amyloid plaques. However, the presence of iron within the different $A \beta$ deposits remains to be further elucidated; a significant fraction 

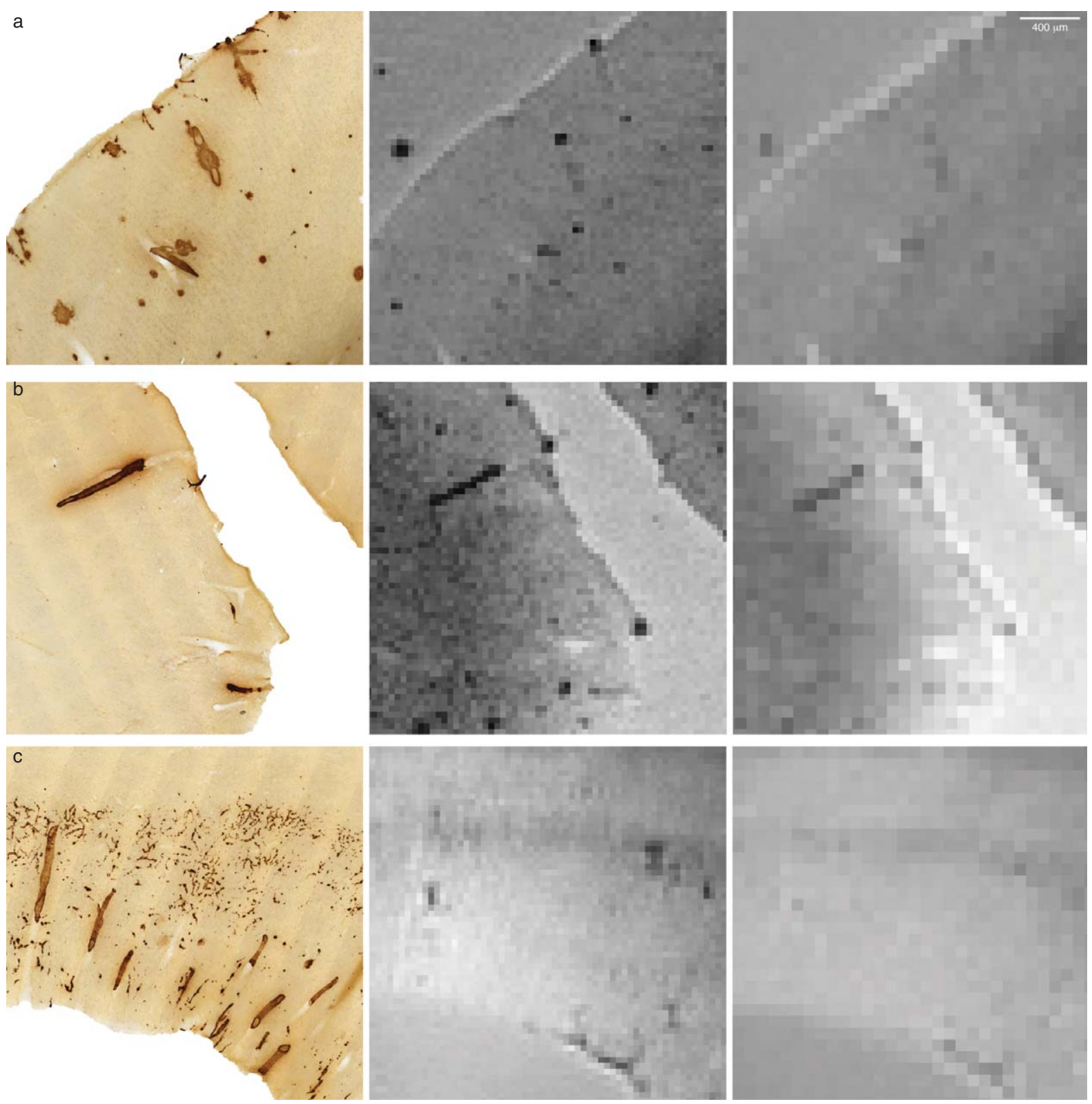

Fig. 6. Detailed $A \beta$ immunohistochemistry with corresponding $T_{2}{ }^{*}$ - and $T_{2}$-weighted images of several types of CAA: (a) dyshoric CAA (subject 14); (b) "large vessel" CAA (subject 12); and (c) both capillary CAA and "large vessel" CAA (subject 13). For (a) and (b) the majority of the CAA could be correlated to similarly-shaped hypo-intense structures. In (c) neither "large vessel" nor capillary CAA were associated with a change in MRI signal intensity.

of amyloid plaques have been reported not to contain any iron [38], whereas several analytical microscopy studies showed a high spatial correlation between amyloid and an increase iron concentration with respect to the surrounding tissue [26, 39, 40]; only one study reported the presence of iron within vascular amyloid other than that associated with microbleeds [41]; and as yet no relation of iron with human diffuse plaques has been reported. The main focus of this study, however, was to investigate the MR characteristics of the different types of $A \beta$ pathology rather than to precisely unravel which constituent is responsible for the observed contrast. The potential role of iron within the non-fibrillar diffuse plaques remains an interesting one, both as a source of MRI contrast and as a neurotoxic species. In a previous study using similar 

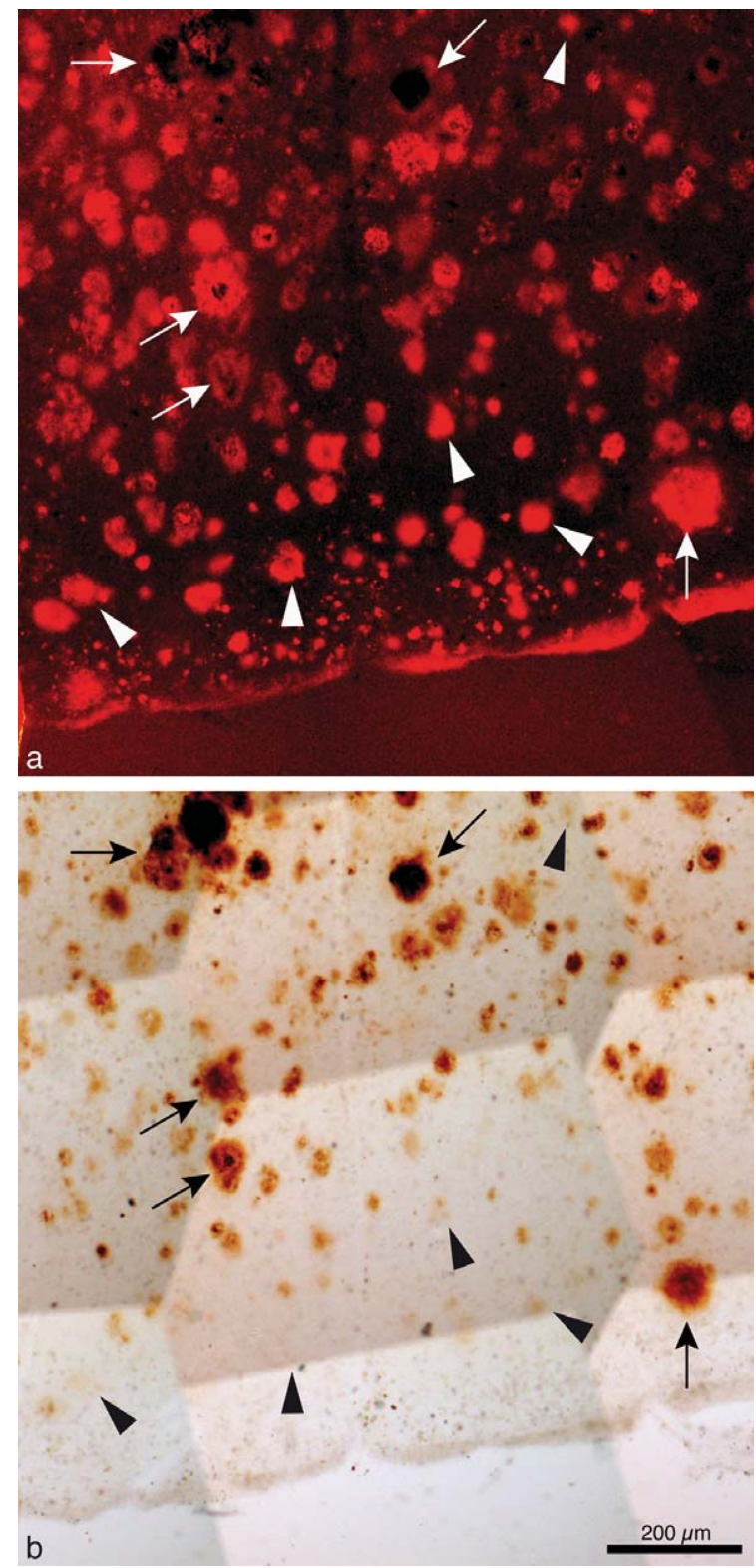

Fig. 7. Detailed immunofluorescence against $A \beta$ (a) with corresponding 3'3-DAB enhanced Perls iron stain (b) (adapted from ref. [7]). In this small cortical areas a wide variety of $A \beta$ deposits both rich (arrows) and low (arrow heads) in iron content is observed. Unable to define the diffuse plaques as the fibrillar status of each $A \beta$ deposit is unknown, therefore it remains unclear whether this might be reflected in the iron colocalization.

sections, we showed that even within a small cortical area, the iron content was highly variable in areas with a relatively similar $A \beta$ load (Fig. 7). Whether this difference can be explained by the presence of amyloid fibrils is yet unclear, because despite several attempts using different histological stains against fibrillar amyloid, we have not been able to perform triple stainings on these thick sections.

In conclusion, direct MR microscopy of histological sections offers a valuable tool to characterize MR changes in relation to different $A \beta$ substrates. The results in this study show that both "large vessel" CAA and parenchymal amyloid cause hypointensities visible on $\mathrm{T}_{2}{ }^{*}$ - and $\mathrm{T}_{2}$-weighted MRI. In contrast, diffuse plaques do not cause any MRI signal changes. These findings provide relevant background information for the interpretation and further development of specific MRI methods for the detection and follow-up of $\mathrm{AD}$ and CAA.

\section{ACKNOWLEDGMENTS}

This research was funded by LeARN, Center for Translational Molecular Medicine. The authors thank Frans Prins and Corry Wellink for technical assistance.

Authors' disclosures available online (http://www.jalz.com/disclosures/view.php?id=1622).

\section{REFERENCES}

[1] Dubois B, Feldman HH, Jacova C, Cummings JL, Dekosky ST, Barberger-Gateau P, Delacourte A, Frisoni G, Fox NC, Galasko D, Gauthier S, Hampel H, Jicha GA, Meguro K, O'Brien J, Pasquier F, Robert P, Rossor M, Salloway S, Sarazin M, de Souza LC, Stern Y, Visser PJ, Scheltens P (2010) Revising the definition of Alzheimer's disease: A new lexicon. Lancet Neurol 9, 1118-1127.

[2] McKhann GM, Knopman DS, Chertkow H, Hyman BT, Jack CR Jr, Kawas CH, Klunk WE, Koroshetz WJ, Manly JJ, Mayeux R, Mohs RC, Morris JC, Rossor MN, Scheltens P, Carrillo MC, Thies B, Weintraub S, Phelps $\mathrm{CH}$ (2011) The diagnosis of dementia due to Alzheimer's disease: Recommendations from the National Institute on Aging-Alzheimer's Association workgroups on diagnostic guidelines for Alzheimer's disease. Alzheimers Dement 7, 263-269.

[3] Frisoni GB, Fox NC, Jack CR Jr, Scheltens P, Thompson PM (2010) The clinical use of structural MRI in Alzheimer disease. Nat Rev Neurol 6, 67-77.

[4] Jack CR Jr, Knopman DS, Jagust WJ, Shaw LM, Aisen PS, Weiner MW, Petersen RC, Trojanowski JQ (2010) Hypothetical model of dynamic biomarkers of the Alzheimer's pathological cascade. Lancet Neurol 9, 119-128.

[5] Benveniste H, Einstein G, Kim KR, Hulette C, Johnson GA (1999) Detection of neuritic plaques in Alzheimer's disease by magnetic resonance microscopy. Proc Natl Acad Sci U S A 96, 14079-14084.

[6] Meadowcroft MD, Connor JR, Smith MB, Yang QX (2009) MRI and histological analysis of beta-amyloid plaques in both human Alzheimer's disease and APP/PS1 transgenic mice. $J$ Magn Reson Imaging 29, 997-1007.

[7] Nabuurs RJ, Hegeman I, Natte R, van Duinen SG, van Buchem MA, van der Weerd L, Webb AG (2011) High-field MRI of single histological slices using an inductively coupled, self-resonant microcoil: Application to ex vivo samples 
of patients with Alzheimer's disease. NMR Biomed 24, 351-357.

[8] van Rooden S, Maat-Schieman ML, Nabuurs RJ, van der Weerd L, van Duijn S, van Duinen SG, Natté R, van Buchem MA, van der Grond J (2009) Cerebral amyloidosis: Postmortem detection with human 7.0-T MR imaging system. Radiology 253, 788-796.

[9] Braakman N, Matysik J, van Duinen SG, Verbeek F, Schliebs R, de Groot HJ, Alia A (2006) Longitudinal assessment of Alzheimer's beta-amyloid plaque development in transgenic mice monitored by in vivo magnetic resonance microimaging. J Magn Reson Imaging 24, 530-536.

[10] Chamberlain R, Reyes D, Curran GL, Marjanska M, Wengenack TM, Poduslo JF, Garwood M, Jack CR Jr (2009) Comparison of amyloid plaque contrast generated by $\mathrm{T} 2$-weighted, $\mathrm{T} 2 *$-weighted, and susceptibility-weighted imaging methods in transgenic mouse models of Alzheimer's disease. Magn Reson Med 61, 1158-1164.

[11] Helpern JA, Lee SP, Falangola MF, Dyakin VV, Bogart A, Ardekani B, Duff K, Branch C, Wisniewski T, de Leon MJ, Wolf O, O'Shea J, Nixon RA (2004) MRI assessment of neuropathology in a transgenic mouse model of Alzheimer's disease. Magn Reson Med 51, 794-798.

[12] Jack CR Jr, Garwood M, Wengenack TM, Borowski B, Curran GL, Lin J, Adriany G, Grohn OH, Grimm R, Poduslo JF (2004) In vivo visualization of Alzheimer's amyloid plaques by magnetic resonance imaging in transgenic mice without a contrast agent. Magn Reson Med 52, 1263-1271.

[13] Jack CR Jr, Wengenack TM, Reyes DA, Garwood M, Curran GL, Borowski BJ, Lin J, Preboske GM, Holasek SS, Adriany G, Poduslo JF (2005) In vivo magnetic resonance microimaging of individual amyloid plaques in Alzheimer's transgenic mice. J Neurosci 25, 10041-10048.

[14] Lee SP, Falangola MF, Nixon RA, Duff K, Helpern JA (2004) Visualization of beta-amyloid plaques in a transgenic mouse model of Alzheimer's disease using MR microscopy without contrast reagents. Magn Reson Med 52, 538-544.

[15] Vanhoutte G, Dewachter I, Borghgraef P, Van LF, Van der Linden A (2005) Noninvasive in vivo MRI detection of neuritic plaques associated with iron in APP[V717I] transgenic mice, a model for Alzheimer's disease. Magn Reson Med 53, 607-613.

[16] Wengenack TM, Reyes DA, Curran GL, Borowski BJ, Lin J, Preboske GM, Holasek SS, Gilles EJ, Chamberlain R, Marjanska M, Jack CR Jr, Garwood M, Poduslo JF (2011) Regional differences in MRI detection of amyloid plaques in AD transgenic mouse brain. Neuroimage 54, 113-122.

[17] Ramani A, Jensen JH, Helpern JA (2006) Quantitative MR imaging in Alzheimer disease. Radiology 241, 26-44.

[18] Duyckaerts C, Delatour B, Potier MC (2009) Classification and basic pathology of Alzheimer disease. Acta Neuropathol 118, 5-36.

[19] Braak H, Braak E (1991) Neuropathological stageing of Alzheimer-related changes. Acta Neuropathol 82, 239-259.

[20] Price JL, Davis PB, Morris JC, White DL (1991) The distribution of tangles, plaques and related immunohistochemical markers in healthy aging and Alzheimer's disease. Neurobiol Aging 12, 295-312.

[21] Thal DR, Rub U, Schultz C, Sassin I, Ghebremedhin E, Del TK, Braak E, Braak H (2000) Sequence of Abeta-protein deposition in the human medial temporal lobe. J Neuropathol Exp Neurol 59, 733-748.

[22] Thal DR, Rub U, Orantes M, Braak H (2002) Phases of A beta-deposition in the human brain and its relevance for the development of AD. Neurology 58, 1791-1800.
[23] Thal DR, Griffin WS, Braak H (2008) Parenchymal and vascular Abeta-deposition and its effects on the degeneration of neurons and cognition in Alzheimer's disease. J Cell Mol Med 12, $1848-1862$.

[24] Thal DR, Griffin WS, de Vos RA, Ghebremedhin E (2008) Cerebral amyloid angiopathy and its relationship to Alzheimer's disease. Acta Neuropathol 115, 599-609.

[25] Attems J (2005) Sporadic cerebral amyloid angiopathy: Pathology, clinical implications, and possible pathomechanisms. Acta Neuropathol 110, 345-359.

[26] Attems J, Jellinger K, Thal DR, Van NW (2011) Review: Sporadic cerebral amyloid angiopathy. Neuropathol Appl Neurobiol 37, 75-93.

[27] Braak H, Alafuzoff I, Arzberger T, Kretzschmar H, Del TK (2006) Staging of Alzheimer disease-associated neurofibrillary pathology using paraffin sections and immunocytochemistry. Acta Neuropathol 112, 389-404.

[28] van Duijn S, Nabuurs RJ, van RS, Maat-Schieman ML, van Duinen SG, van Buchem MA, van der Weerd L, Natte R (2011) MRI artifacts in human brain tissue after prolonged formalin storage. Magn Reson Med 65, 1750-1758.

[29] Pfefferbaum A, Sullivan EV, Adalsteinsson E, Garrick T, Harper C (2004) Postmortem MR imaging of formalin-fixed human brain. Neuroimage 21, 1585-1595.

[30] Shepherd TM, Thelwall PE, Stanisz GJ, Blackband SJ (2009) Aldehyde fixative solutions alter the water relaxation and diffusion properties of nervous tissue. Magn Reson Med 62, 26-34.

[31] Natte R, Maat-Schieman ML, Haan J, Bornebroek M, Roos RA, van Duinen SG (2001) Dementia in hereditary cerebral hemorrhage with amyloidosis-Dutch type is associated with cerebral amyloid angiopathy but is independent of plaques and neurofibrillary tangles. Ann Neurol 50, 765-772.

[32] Ikonomovic MD, Klunk WE, Abrahamson EE, Mathis CA, Price JC, Tsopelas ND, Lopresti BJ, Ziolko S, Bi W, Paljug WR, Debnath ML, Hope CE, Isanski BA, Hamilton RL, Dekosky ST (2008) Post-mortem correlates of in vivo PiBPET amyloid imaging in a typical case of Alzheimer's disease. Brain 131, 1630-1645.

[33] Lockhart A, Lamb JR, Osredkar T, Sue LI, Joyce JN, Ye L, Libri V, Leppert D, Beach TG (2007) PIB is a non-specific imaging marker of amyloid-beta (Abeta) peptide-related cerebral amyloidosis. Brain 130, 2607-2615.

[34] Burack MA, Hartlein J, Flores HP, Taylor-Reinwald L, Perlmutter JS, Cairns NJ (2010) In vivo amyloid imaging in autopsy-confirmed Parkinson disease with dementia. Neurology 74, 77-84.

[35] Kantarci K, Yang C, Schneider JA, Senjem ML, Reyes DA, Lowe VJ, Barnes LL, Aggarwal NT, Bennett DA, Smith GE, Petersen RC, Jack CR Jr, Boeve BF (2012) Ante mortem amyloid imaging and beta-amyloid pathology in a case with dementia with Lewy bodies. Neurobiol Aging 33, 878-885.

[36] Schrag M, Dickson A, Jiffry A, Kirsch D, Vinters HV, Kirsch W (2010) The effect of formalin fixation on the levels of brain transition metals in archived samples. Biometals 23, 11231127.

[37] Antharam V, Collingwood JF, Bullivant JP, Davidson MR, Chandra S, Mikhaylova A, Finnegan ME, Batich C, Forder JR, Dobson J (2012) High field magnetic resonance microscopy of the human hippocampus in Alzheimer's disease: Quantitative imaging and correlation with iron. Neuroimage $\mathbf{5 9}$, 1249-1260.

[38] Collingwood JF, Chong RK, Kasama T, Cervera-Gontard L, Dunin-Borkowski RE, Perry G, Posfai M, Siedlak SL, Simpson ET, Smith MA, Dobson J (2008) Three-dimensional 
tomographic imaging and characterization of iron compounds within Alzheimer's plaque core material. J Alzheimers Dis $\mathbf{1 4}$ 235-245.

[39] Miller LM, Wang Q, Telivala TP, Smith RJ, Lanzirotti A, Miklossy J (2006) Synchrotron-based infrared and X-ray imaging shows focalized accumulation of $\mathrm{Cu}$ and $\mathrm{Zn}$ co-localized with beta-amyloid deposits in Alzheimer's disease. J Struct Biol 155, 30-37.

[40] Quintana C, Bellefqih S, Laval JY, Guerquin-Kern JL, Wu TD, Avila J, Ferrer I, Arranz R, Patino C (2006) Study of the localization of iron, ferritin, and hemosiderin in Alzheimer's disease hippocampus by analytical microscopy at the subcellular level. J Struct Biol 153, 42-54.

[41] Schrag M, Crofton A, Zabel M, Jiffry A, Kirsch D, Dickson A, Mao XW, Vinters HV, Domaille DW, Chang CJ, Kirsch W (2011) Effect of cerebral amyloid angiopathy on brain iron, copper, and zinc in Alzheimer's disease. J Alzheimers Dis 24, $137-149$. 